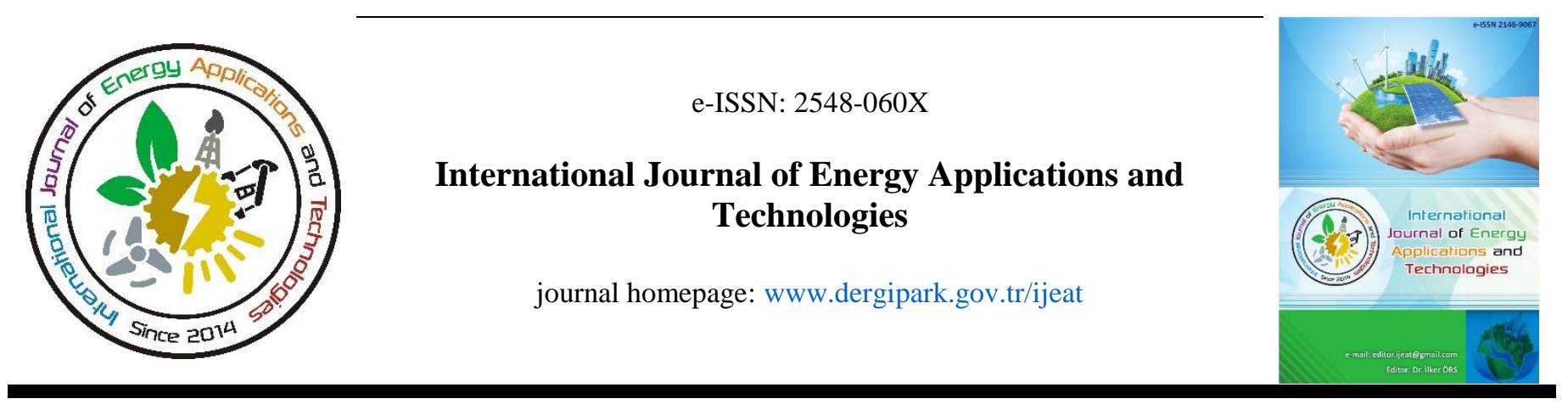

Original Research Article

\title{
Drag reduction of a bus model by passive flow canal
}

\author{
Cihan Bayındırlı \\ Nigde Vocational School of Technical Sciences, Nigde Omer Halisdemir University, Nigde, 51000, Turkey
}

\author{
ARTICLE INFO \\ * Corresponding author \\ cbayindirli@ohu.edu.tr \\ Received February 28, 2019 \\ Accepted March 23, 2019 \\ Published by Editorial Board \\ Members of IJEAT \\ (C) This article is distributed by \\ Turk Journal Park System under \\ the CC 4.0 terms and conditions. \\ doi: 10.31593/ijeat.533745
}

\begin{abstract}
In this study, the drag force of 1/33 scale bus model was improved by passive flow control method. The effect of passive air canal application to drag coefficient was experimentally and numerically investigated on a bus model. Experiments were carried out in the range of $3.8 \times 10^{5}$ - 7.9x $10^{5}$ Reynolds numbers. The similarity conditions were provided in experimental studies with the exception of the moving road. To provide the geometric similarity condition, the model bus was produced in 3D printer by scanning 3 dimensions. Reynolds number independence was used for dynamic similarity condition. The rate of blockage is $6.81 \%$ for kinematic similarity, which is lower than the rate of blockage accepted in the literature. Respectively $4.21 \%, 7.48 \%$ and $12.19 \%$ aerodynamic improvement achieved with 1,3 , and 5 passive air canals whose diameter $6 \mathrm{~mm}$. Flow analysis was performed in Fluent ${ }^{\circledR}$ program of the model 3 bus to view the flow structure around the bus. The numerical results support to wind tunnel results. In this study the effect of obtained aerodynamic improvements by applied passive flow control method can decrease fuel consumption about $2-6 \%$ at high vehicle speeds.
\end{abstract}

\section{Introduction}

The aerodynamic force significantly affects the performance and fuel consumption of vehicles. Besides road holding features, emission values and comfort of vehicles are related to aerodynamic shape. The improving the fuel economy of vehicles will have impact on energy security, greenhouse emissions and petrol based fuel costs. Automotive manufacturers are competing to produce powerful cars with better fuel efficiency. The fuel consumption of vehicles can be improved by reducing the drag coefficient by active or passive flow control methods to reduce the aerodynamic drag. There are many drag reduction techniques in literature both passive flow control and active flow control. The fuel consumption by vehicles accounts for over $30 \%$ of $\mathrm{CO}_{2}$ and other greenhouse gas (GHG) emissions. Moreover, most of the usable energy from the engine goes into overcoming the aerodynamic drag (53\%) and rolling resistance (32\%); only $9 \%$ is required for auxiliary equipment and $6 \%$ is used by the drive-train. $15 \%$ reduction in aerodynamic drag at highway speed of 55mph can result in about 5-7\% in fuel saving [1]. The effect of multiple bumps application to aerodynamic force was investigated. It was placed in the rear end of the cabin roof on the overall aerodynamic drag reduction for a generic model of a commercial investigated and optimized. The numerical method combined automatic redesign of the add-ons, simulation, and optimization using a globalized form of the Taguchi method. The numerical optimization showed that drag reduction can be achieved at different values of the design parameters with an overall expected reduction between 6 and 10\%. Overall, the bumps increased the cabin surface pressure coefficient and displaced the attachment of the bed flow over the tailgate toward the cabin, eventually reducing the size of the recirculating flow behind 
the tailgate and improving the pressure there [2]. The drag coefficient was decreased by using active flow control method in that study [3]. As passive flow control, bumper design was changed and drag force improved the up to $3.08 \%$ with the in accordance with reference model [4]. The drag coefficient was reduced by $3 \%-9 \%$ by regularly air jetting behind the model [5]. The flow structure around of a bus model was experimentally investigated. They studied the average and instantaneous acceleration vector map, swirl spins, flow line topology and other turbulence properties by PIV (particle image velocimetry) method [6]. The mechanism of moving vehicle's transient aerodynamic force was investigated in crosswind by CFD method [7]. In CFD studies the change in turbulence intensity does not change the pressure distribution on the model [8]. The aerodynamic structure of a truck trailer model was examined by the CFD method and the $C_{D}$ coefficient of the truck trailer model was improved by $21 \%$ by adding passive flow control components [9]. They examined the flow structure around a bus model using the CFD method. They developed three models to reduce the drag force of the bus model. They achieved an aerodynamic improvement as respectively $6.57 \%, 25.82 \%$ and $24.42 \%$ [10].

This study focused on to decrease the aerodynamic force of a bus model whose drag coefficient experimentally and numerically determined in study of Bayindirli and Çelik, 2018 [11]. Passive flow canal applications were used to minimization of drag coefficient both in a wind tunnel and CFD method. The numerical simulations were evaluated using the commercial software Ansys - Fluent ${ }^{\circledR}$, a widely accepted as computational analysis technique which works with the finite volume method. It was obtained that the

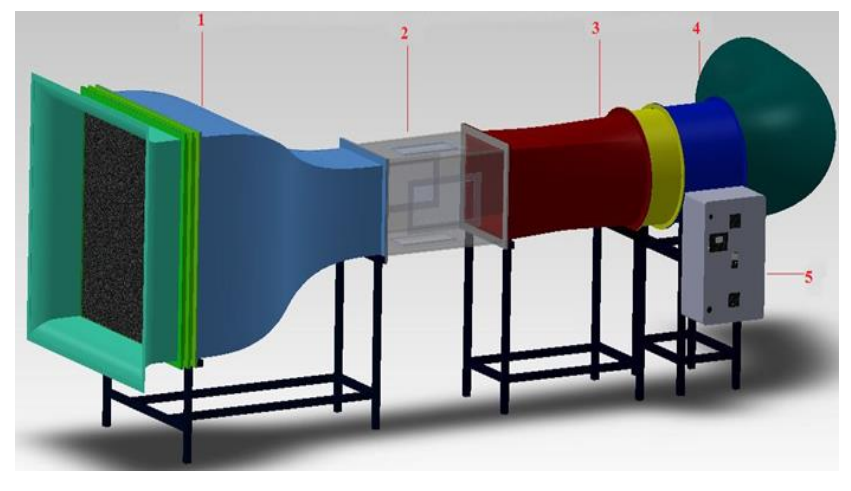

1:Throttling cone 2:Test area 3:Diffuser 4:Fan unit 5:Frequency inverter

Figure 1a. Experimental setup

In experimental studies, a Honeywell Model 41 load cell was used to measure the drag force with $0.1 \%$ accuracy which measures 0-5 lb force, with $0-5 \mathrm{Vdc}$ output voltages. During the force measurement, total of 20000 data were acquired for 20 seconds at $1000 \mathrm{~Hz}$ frequency at each free stream velocity and the average of this 20000 value was taken as drag force. numerical results support experimental results after CFD simulations.

\section{Material and Methods in Wind Tunnel Tests}

\subsection{Similarity conditions}

In studies on vehicle aerodynamics, three different similarity conditions must be provided between prototype and model car. These are geometric, kinematic and dynamic similarity conditions. To provide geometric similarity, the licensed model bus has been used and faults that may occur due to surface roughness, very small parts are ignored. In kinematic similarity the rate of blockage is determinant factor. The front surface area of model bus is $0.01089 \mathrm{~m}^{2}$; front surface area of test area is $0.16 \mathrm{~m}^{2}$ and a blockage rate is $6.81 \%$. The blocking rate should be lower than $7.5 \%$ in literature [12]. Reynolds number independence was used to provide dynamic similarity in the study.

\subsection{Experimental setup}

The experiments were conducted in the test section of a lowspeed, suction-type wind tunnel with a square test section of $400 \mathrm{~mm} \times 400 \mathrm{~mm} \times 1000 \mathrm{~mm}$. The $4 \mathrm{~kW}$ powered axial fan motor was used to achieve desired free stream velocity in the test region. The rpm of fan motor was controlled by frequency inverter. The frequency inverter operates in the range of $0-50 \mathrm{~Hz}$ and has $0.1 \mathrm{~Hz}$ step. The wind tunnel tests were carried out in the range of $3.8 \times 10^{5}-7.9 \times 10^{5}$ Reynolds numbers, based on length of bus models. The minimum and maximum free stream velocity in the range of $0-30 \mathrm{~m} / \mathrm{s}$ in wind tunnel. The view of the test devices and wind tunnel is given in Fig. 1a,b.

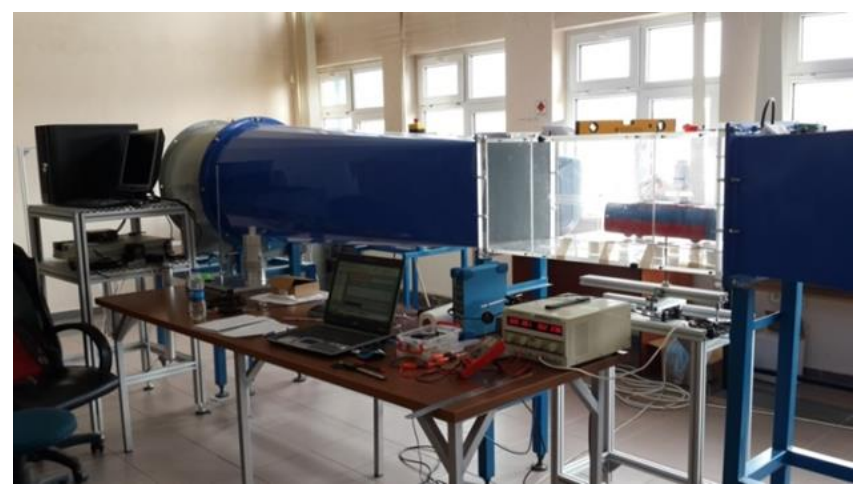

Figure1b. Experimental setup [11]

The free stream velocity of the wind tunnel was calculated with a pitot tube. The 24-bit OROS OR35 real-time multianalyzer, external recorder with a $40 \mathrm{kHz}$ sampling frequency and OROS Navigate data acquisition software were used to collect voltage outputs from the load cell. The experiments were performed on the test model which is 
shown in Figure 2-4. In this study, the bus model which is examined and improved aerodynamically is $1 / 33$ scaled model of real vehicle. A 1/66 scaled toy bus was precisely scanned with three-dimensional scanning device and was created by computer-aided drawing method. It was double scaled and produced in $3 \mathrm{D}$ printer as $1 / 33$ scaled due to measure of very little drag forces needs very sensitive test devices. The model bus positioned on floor plate in $5 \mathrm{~cm}$ high. So uniform flow effected to model vehicle. The size of model bus $101 \times 96.3 \times 441 \mathrm{~mm}$.

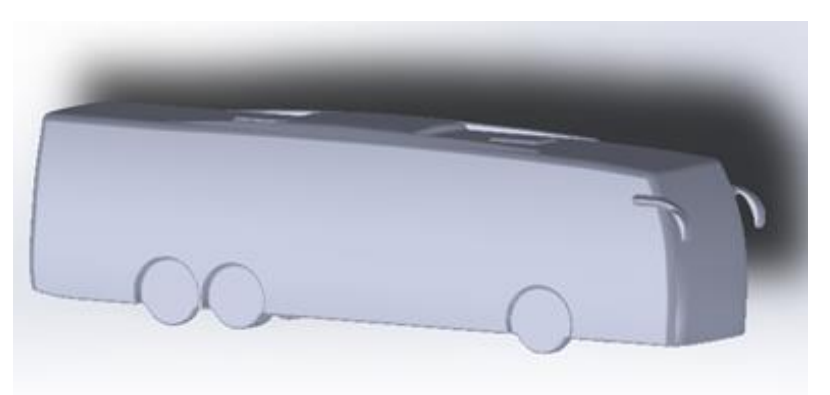

Figure 2. Drawing data of bus model [11]

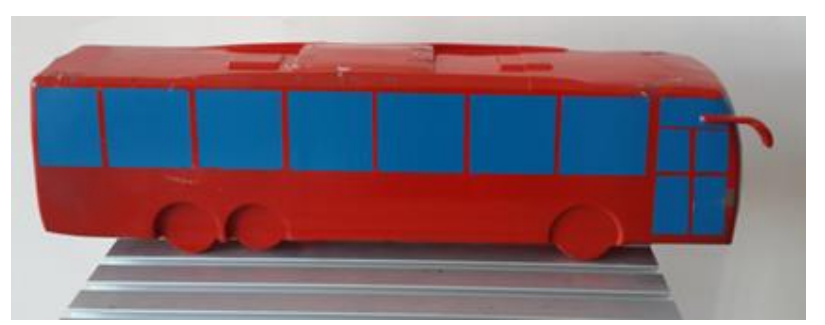

Figure 3. The produced bus model in 3D printer [11]

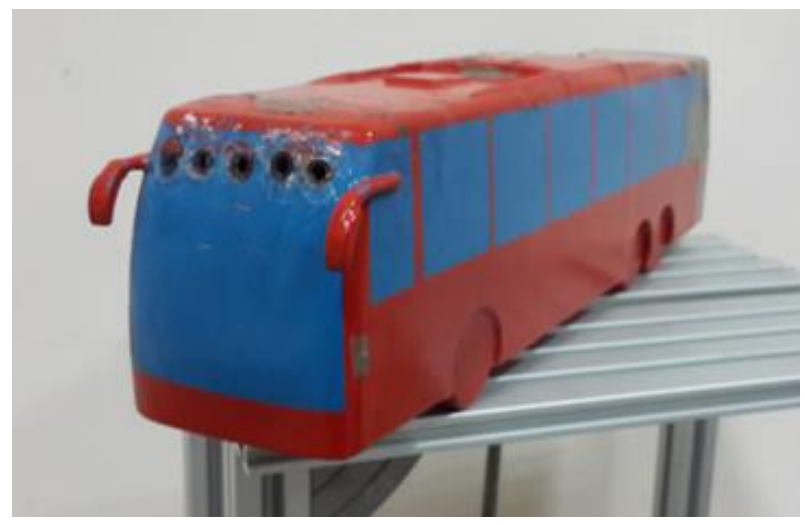

Figure 4. Passive flow canals application on model bus

\subsection{Uncertainty analysis of experimental results}

In this study, the results of the uncertainty analysis of the calculated. Uncertainty value for the $\mathrm{Re}$ number was obtained as $3,87 \%$ by writing $\rho$, UPitot, $H$ and $\mu$ argument of uncertainty values. The uncertainty values of drag forces were obtained as $4.5 \%$. It was calculated for $10 \mathrm{~m} / \mathrm{s}$ free flow speed and $\operatorname{Re}=312000$ value. The uncertainty value of the drag force coefficient was obtained as $4.7 \%$.by writing $\mathrm{F}$, $\rho, A$, the argument of uncertainty values [11].

\subsection{Methodology in CFD}

In study, convergence criteria was taken as $1 \times 10^{-3}$ for continuity, x-velocity, $y$-velocity and z-velocity. The intensity of turbulence is also taken as $1 \%$. The air density is taken as $1 \mathrm{~kg} / \mathrm{m}^{3}$ and the dynamic viscosity is $1.56 \times 10^{-5}$. The front surface area of the vehicle is calculated as $0.01089 \mathrm{~m} 2$ from the reports-projected area. The analyses were made as standard initialization using standard wall functions and Simple Least Squared Cell Based k- $\varepsilon$ RNG turbulence model. The numeric flow analyses were carried out in the Fluent ${ }^{\circledR}$ program using Workstation computer which has Intel® Xeon ${ }^{\circledR}$ CPU E3-1270 V5 $3.60 \mathrm{GHz}$ processor and $32 \mathrm{~Gb}$ Ram.

\subsubsection{General equations}

Continuity and momentum equations are used in solving the finite volumes with computational flow dynamics (CFD). In practice, it is difficult to solve these equations analytically. Therefore, these equations are solved numerically using CFD packet programs.

Continuity and momentum equations are used in solving the finite volumes with computational flow dynamics (CFD). In practice, it is difficult to solve these equations analytically. Therefore, these equations are solved numerically using CFD packet programs.

\section{Continuity equation}

The continuity equation is expressed as the mass balance in the control volume in a flow.

$\frac{\partial u}{\partial x}+\frac{\partial v}{\partial y}+\frac{\partial w}{\partial z}=0$

Momentum equation

According to Newton's second law, the rate of change of the momentum of a fluid fraction is equal to the total of the forces acting on that fluid fraction. The momentum increase rate in the $\mathrm{x}, \mathrm{y}$ and $\mathrm{z}$ directions of the unit volume of a fluid fraction is respectively expressed in terms of $\rho \frac{D u}{D t}, \rho \frac{D v}{D t} \rho \frac{D w}{D t}$ [13].

The $\mathrm{x}$-component of the momentum equation;

$\rho \frac{D u}{D t}=\frac{\partial\left(-p+\tau_{x x}\right)}{\partial x}+\frac{\partial \tau_{y x}}{\partial y}+\frac{\partial \tau_{z x}}{\partial z}+S_{M_{x}}$

The y-component of the momentum equation;

$\rho \frac{D v}{D t}=\frac{\partial \tau_{x y}}{\partial x}+\frac{\partial\left(-p+\tau_{y y}\right)}{\partial y}+\frac{\partial \tau_{z y}}{\partial z}+S_{M y}$

The $\mathrm{z}$-component of the momentum equation;

$\rho \frac{D w}{D t}=\frac{\partial \tau_{x z}}{\partial x}+\frac{\partial \tau_{y z}}{\partial y}+\frac{\partial\left(-p+\tau_{z z}\right)}{\partial z}+S_{M_{z}}$

$\underline{\text { Navier }- \text { Stokes equations }}$

Navier - Stokes and continuity equations are also referred to as differential motion equations. When these equations are solved, some assumptions are taken and pressure and three components of velocity ( $\mathrm{x}, \mathrm{y}, \mathrm{z})$ are calculated [13]. The most 
useful way to develop the finite volume method of Navier Stokes equations;

$\rho \frac{D u}{D t}=-\frac{\partial p}{\partial x}+\operatorname{div}(\mu \operatorname{grad} u)+S_{M_{x}}$

$\rho \frac{D v}{D t}=-\frac{\partial p}{\partial y}+\operatorname{div}(\mu \operatorname{grad} v)+S_{M y}$

$\rho \frac{D w}{D t}=-\frac{\partial p}{\partial z}+\operatorname{div}(\mu \operatorname{grad} w)+S_{M z}$

The sizes of solution domain is same with experimental test area where $40 \times 40 \times 100 \mathrm{~cm}$. In this section as seen in Fig. 5, the mold cavity of the model vehicle is formed, the drawing data are defined and transferred to the meshing section. The boundary conditions are defined as inlet, outlet, wall and bus model wall in solution area.

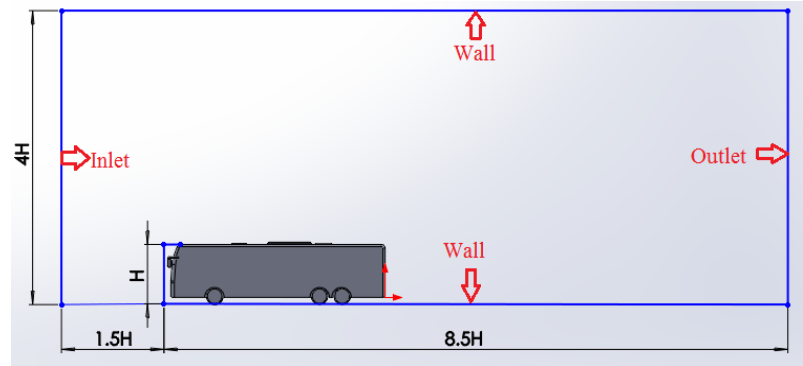

Figure 5. Computational domain and the boundary conditions

\subsection{Grid strategy}

An unstructured tetrahedral mesh structure was used in all computational domains, refined in almost all surfaces of the bus models and in regions where the flow has high gradients. Proximity and curvature grids were used to obtain fine mesh distribution. Moreover, a grid independence study was carried out in order to guarantee the element size does not affect the results. The bus model positioned in a box whose sizes $50 \times 50 \times 50 \mathrm{~mm}$. To capture certain areas of interest the cells have to small enough to solve all irregularities and achieve fine solution. The tight mesh structure was created on bus model and flow separation area where separation might occur and turbulence is high. 3527539 triangular volumes cell structure (tetrahedrons) was created in solution domain. The mesh distribution on model bus 3 is given Fig. 6.

The aerodynamic drag coefficient $C_{D}$ is the function of the drag force $F_{D}$, density $\rho$, free stream velocity $V$ and front view area and it is given in Eq. (8).

$$
\mathrm{C}_{\mathrm{D}}=\frac{F_{D}}{1 / 2 \rho \mathrm{V}^{2} \mathrm{~A}}
$$
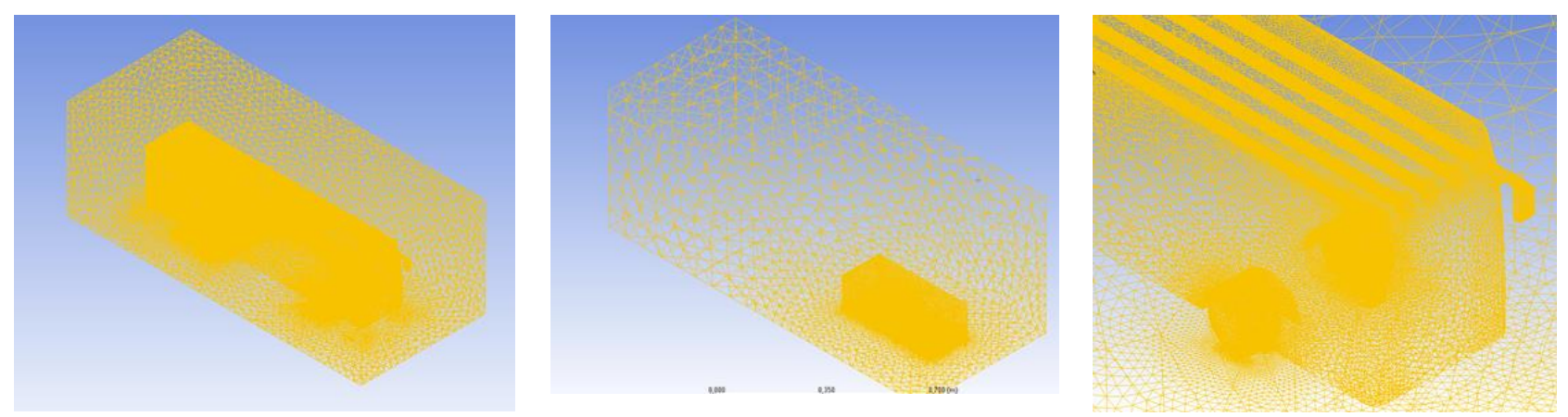

Figure 6. Mesh distribution on model 3 bus

\subsection{Mesh independent in CFD analysis}

It is very important to establish a smooth and high quality mesh in the numerical analysis about the finite volumes in terms of the correctness of the results. Therefore, mesh quality is sought in numerical studies. However, as the complexity of the analyzed geometries increases, it becomes more difficult to obtain desired mesh quality. The bus model has small, curved parts. In this case, the mesh quality could not be obtained at the desired level. In order to achieve desired mesh quality, it will be necessary to further simplify of drawing data, draw flat parts instead of arcuate parts, or to close small parts and create a larger number of mesh structures. In this case, the drawing data will move away from the geometric similarity. In this study, the average element quality was 0.68 . It is not recommended that this value be higher than 0.5 . One of the methods to verify numerical studies with independence tests from the mesh. If the result does not change after a certain value despite the increase in the number of mesh in the numerical solution, independence in the solution from the mesh is obtained. In this study, as shown in Table 1. mesh independence tests were carried out for 10 different triangular volumes (tetrahedrons) mesh structure at $5.4 \times 10^{5}$ Reynolds number for model bus. The mesh independent analyzes were carried out by changing the minimum and maximum dimensions of the triangular mesh in the mesh configurations of the bus and the desired mesh number structures were created at different skewness rates.

The independence tests from the mesh were conducted on 10 different mesh numbers. As seen in Fig. 7, the $C_{D}$ coefficient was obtained at approximate values after 1550251 mesh numbers. In this study, the number of mesh was determined as 3527539. These mesh number is in the region where the mesh independence is obtained. Therefore, it has been 
accepted that flow analyzes are performed independently from the mesh quality. The faults which were caused mesh number and quality in numerical results were ignored.

Table 1. Mesh independence test results at $5.4 \times 10^{5}$ Reynolds number

\begin{tabular}{ccc}
\hline Reynolds Number & Mesh Number & $\mathbf{C}_{\mathbf{D}}$ \\
\hline $\mathbf{5 4 4} \mathbf{4 5 3}$ & 650306 & 0.56 \\
$\mathbf{5 4 4} \mathbf{4 5 3}$ & 954520 & 0.72 \\
$\mathbf{5 4 4} \mathbf{4 5 3}$ & 1060230 & 0.68 \\
$\mathbf{5 4 4} \mathbf{4 5 3}$ & 1550251 & 0.66 \\
$\mathbf{5 4 4} \mathbf{4 5 3}$ & 1995742 & 0.64 \\
$\mathbf{5 4 4 4 5 3}$ & 2227102 & 0.66 \\
$\mathbf{5 4 4} \mathbf{4 5 3}$ & 2602154 & 0.65 \\
$\mathbf{5 4 4} \mathbf{4 5 3}$ & $\mathbf{3 5 2 7} \mathbf{5 3 9}$ & $\mathbf{0 . 6 5}$ \\
$\mathbf{5 4 4} \mathbf{4 5 3}$ & 5160468 & 0.66 \\
$\mathbf{5 4 4} \mathbf{4 5 3}$ & 6011160 & 0.64 \\
\hline
\end{tabular}

The independence tests from the mesh were conducted on 10 different mesh numbers. As seen in Fig. 7, the $C_{D}$ coefficient was obtained at approximate values after 1550251 mesh numbers. In this study, the number of mesh was determined as 3527539 . These mesh number is in the region where the mesh independence is obtained. Therefore, it has been accepted that flow analyzes are performed independently from the mesh quality. The faults which were caused mesh number and quality in numerical results were ignored.

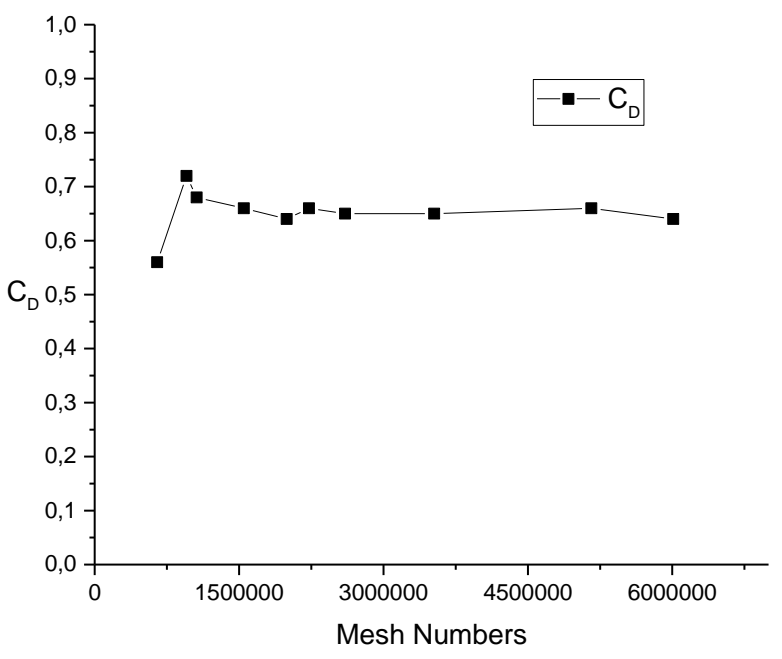

Figure 7. The graph of mesh independent

\section{Experimental Results}

As seen in Table 2 and Fig. 8, as a result of experimental tests the $\mathrm{C}_{\mathrm{D}}$ coefficient of the model bus was determined as 0.633 average. In this study, passive air canals whose inner diameter $6 \mathrm{~mm}$, wall thickness $2 \mathrm{~mm}$, length $410 \mathrm{~mm}$ are added to the roof area of the model bus. Respectively 1, 3 and 5 canals were drilled on the roof area of bus model. The effect of transferring of the flow from front surface area to the negative pressure area behind the bus determined by the experimental method.

Table 2. The drag coefficient values of model buses in wind tunnel

\begin{tabular}{ccccc}
\hline Reynolds Number & Base Bus Model $\mathbf{C}_{\mathbf{D}}$ & $\begin{array}{c}\text { Model 1 } \mathbf{C}_{\mathbf{D}} \\
\text { (1 Canal) }\end{array}$ & $\begin{array}{c}\text { Model 2 } \mathbf{C}_{\mathbf{D}} \\
\text { (3 Canals) }\end{array}$ & $\begin{array}{c}\text { Model 3 } \mathbf{C}_{\mathbf{D}} \\
\text { (5 Canals) }\end{array}$ \\
\hline $\mathbf{3 8 2 8 6 6}$ & 0.583 & 0.441 & 0.545 & 0.415 \\
$\mathbf{4 6 5 4 2 6}$ & 0.630 & 0.600 & 0.614 & 0.570 \\
$\mathbf{5 4 4 4 5 3}$ & 0.629 & 0.619 & 0.618 & 0.582 \\
$\mathbf{6 2 9 1 1 2}$ & 0.654 & 0.623 & 0.623 & 0.580 \\
$\mathbf{7 1 2 8 5 7}$ & 0.653 & 0.633 & 0.613 & 0.584 \\
$\mathbf{7 9 2 9 0 0}$ & 0.651 & 0.599 & 0.626 & 0.605 \\
Average & $\mathbf{0 . 6 3 3}$ & $\mathbf{0 . 5 8 6}$ & $\mathbf{0 . 6 0 7}$ & $\mathbf{0 . 5 5 6}$ \\
Drag Reduction & & $\mathbf{4 . 2 1 \%}$ & $\mathbf{7 . 4 8 \%}$ & $\mathbf{1 2 . 1 9 \%}$ \\
\hline
\end{tabular}

The drag coefficient of a truck trailer was experimentally reduced by $25.58 \%$ by using spoiler. Also they used passive flow canal to decrease drag coefficient. The drag coefficient of a truck trailer model was decreased $22.46 \%$ by using together; spoiler, passive flow canal and redirector in a wind tunnel [14]. In this study passive flow canal applications were applied to reduce the pressure induced aerodynamic drag and positive results were obtained on a bus model. With this passive flow control method, the $C_{D}$ coefficient of the bus was improved between the rates of $4.21 \%-12.19 \%$ without energy consume.

\section{The Numerical Flow Analysis of Model 3 in CFD}

As a result of the wind tunnel tests, the maximum drag reduction obtained in model 3 bus as $12.19 \%$. The flow analysis of base bus model and model 3 bus conducted in CFD method also. The flow structure around of bus and pressure distribution on bus model determined as seen in Fig. 10-12. As seen in Table 3 and Fig. 9, 11.93\% drag reduction obtained by 5 passive flow canals in model 3 bus by using CFD. This result confirms experimental improvements also. 


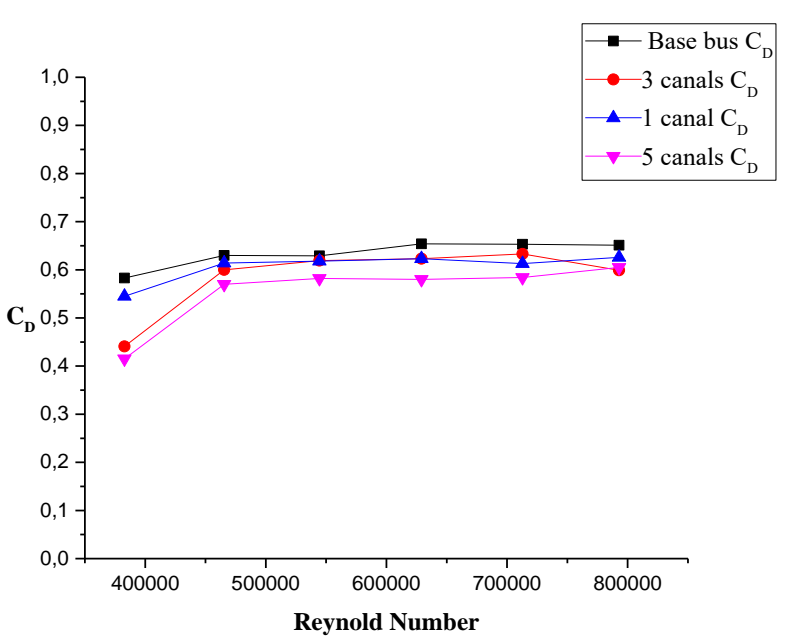

Figure 8. The graph of drag coefficient of model buses

Table 3. The drag reduction in model 3 bus in CFD

\begin{tabular}{ccc}
\hline $\begin{array}{c}\text { Reynolds } \\
\text { Number }\end{array}$ & $\begin{array}{c}\text { Model 3 } \\
\text { CFD C }_{\mathbf{D}}\end{array}$ & $\begin{array}{c}\text { Base model } \\
\text { CFD C }_{\mathbf{D}}\end{array}$ \\
\hline $\mathbf{3 8 2 8 6 6}$ & 0.611 & 0.659 \\
$\mathbf{4 6 5 4 2 6}$ & 0.586 & 0.661 \\
$\mathbf{5 4 4 4 5 3}$ & 0.569 & 0.668 \\
$\mathbf{6 2 9 1 1 2}$ & 0.547 & 0.647 \\
$\mathbf{7 1 2 8 5 7}$ & 0.547 & 0.608 \\
$\mathbf{7 9 2 9 0 0}$ & 0.548 & 0.625 \\
Average & $\mathbf{0 . 5 6 8}$ & $\mathbf{0 . 6 4 5}$ \\
\hline Drag Reduction & & $\mathbf{\% 1 1 . 9 3 ~ i n ~ C F D ~}$ \\
\hline
\end{tabular}

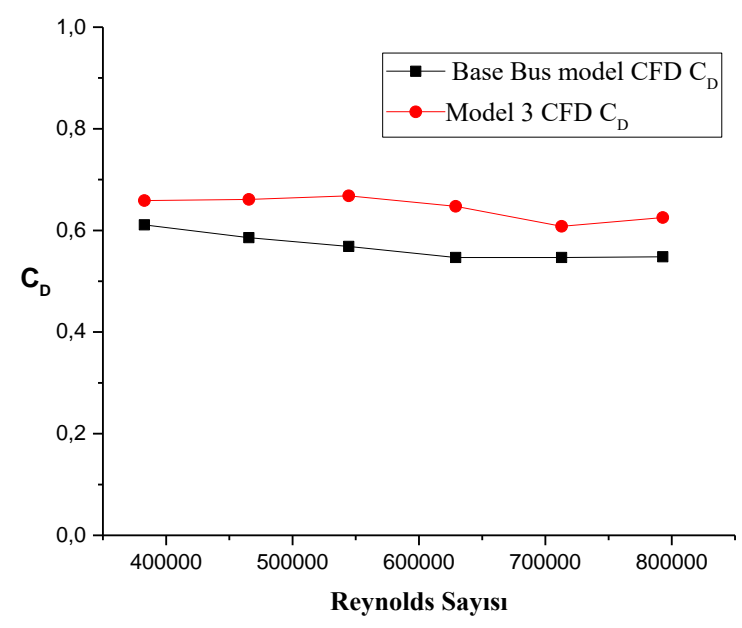

Figure 9. The drag reduction in model 3 using CFD

As seen in the CFD flow analysis, the total drag force of the vehicles is mostly pressure based. This pressure is positive and negative, but the area of the negative pressure zone is considerably higher positive pressure area. In vector and streamline display of the flow, it is observed that the flow separates after leaving the windshield surface. Also there is turbulence area rear of the bus. This negative pressure area creates aerodynamic drag the opposite direction to the forward movement of the vehicle. By using passive flow canal application, the flow where on front surface was transferred through the canals to the negative pressure area of the bus and the aerodynamic drag force was reduced.

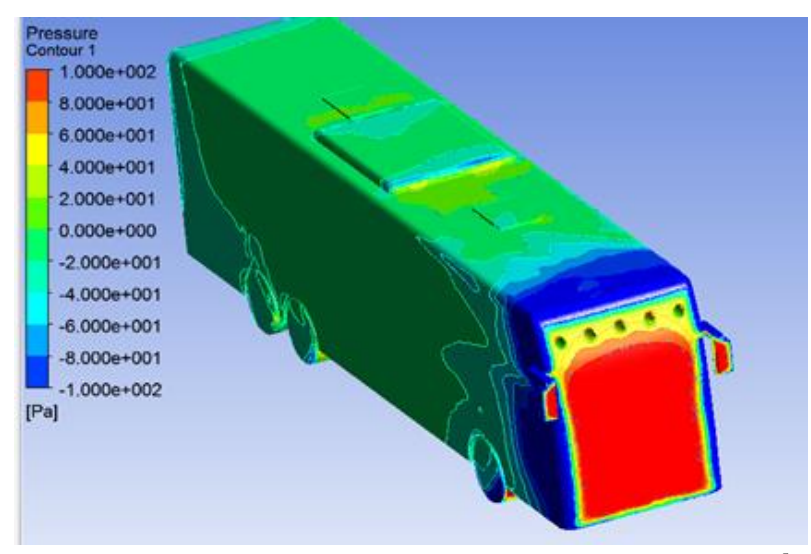

Figure 10. The pressure distribution on the model 3 bus at $5.4 \times 10^{5}$

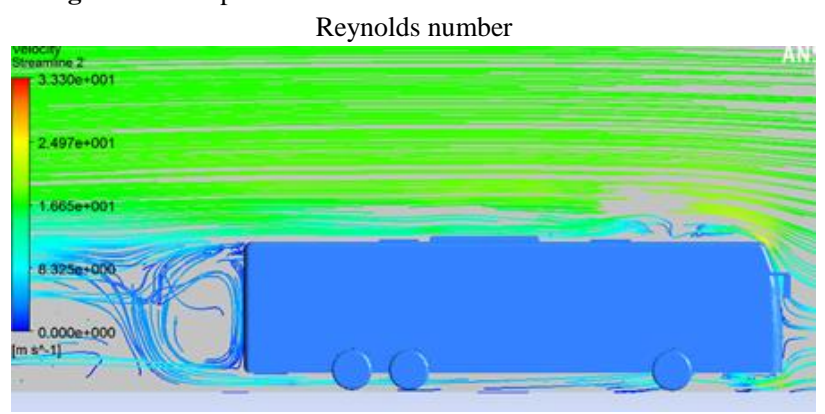

Figure11. The streamline image of model 3 bus at $5.4 \times 10^{5}$ Reynolds number

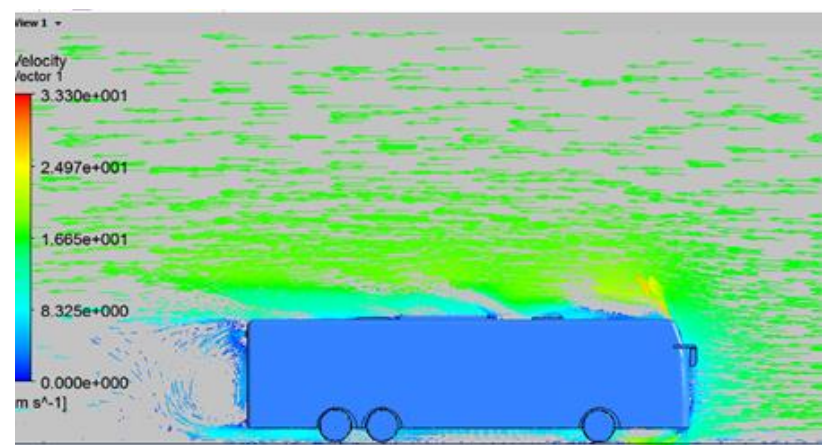

Figure 12a.The vector image of model 3 at $5.4 \times 10^{5}$ Reynolds number

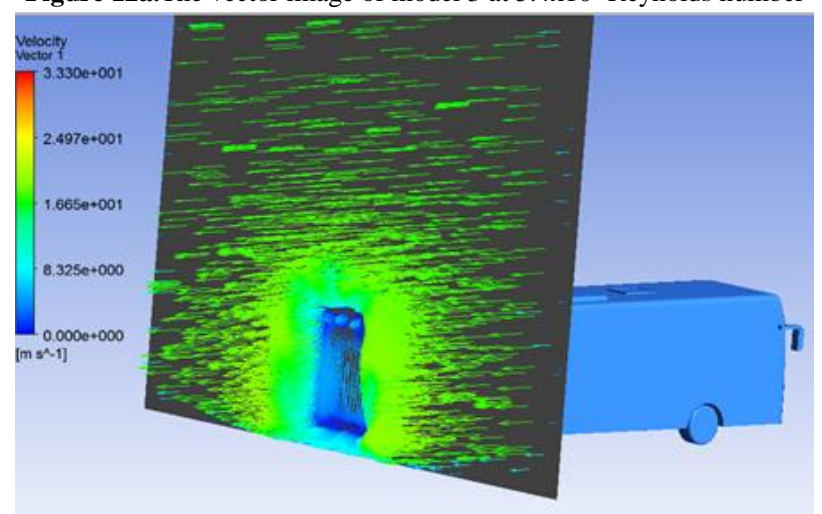

Figure 12b.The vector image of model 3 at $5.4 \times 10^{5}$ Reynolds number 


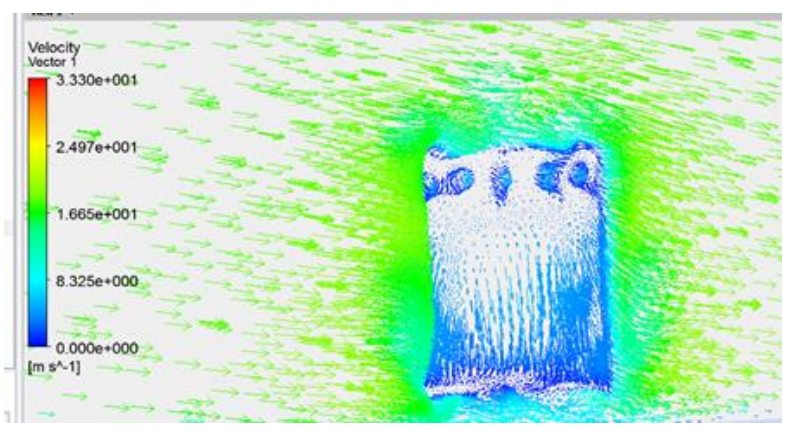

Figure 12c. The vector image of model 3 at $5.4 \times 10^{5}$ Reynolds number

\section{Conclusion}

In this study, aerodynamic improvement was obtained by passive flow control method in a bus model. All similarity conditions except the moving floor were provided in the experimental studies. Passive air canal application was applied to the upper roof area of the bus to provide aerodynamic improvement. By the experimental method, air flow was carried to the back of the bus with inner diameter of $6 \mathrm{~mm}$ plastic canals. Passive air canals reduce the pressureinduced drag force by filling the negative pressure zone of the bus with air. In the study, the highest aerodynamic improvement was provided in model 3 bus with 5 passive air canals. The $\mathrm{C}_{\mathrm{D}}$ coefficient of the model 3 bus was 0.556 and the aerodynamic recovery rate was $12.18 \%$. The effect of the aerodynamic reduction at this rate can decrease fuel consumption about $6 \%$ at high speeds. In order to view the flow structure around the model 3 bus, flow analysis was performed by CFD method under the same experimental conditions. The coefficient of the model 3 bus was 0.567 and the aerodynamic recovery rate was $11.93 \%$. The difference between the two methods is $2.06 \%$. The numerical results support experimental results.

\section{Acknowledgement}

This study was supported by Niğde Ömer Halisdemir University Scientific Research Projects Coordination Unit with ref. FEB 2016/24 BAGEP. The author would like to thank to Niğde Ömer Halisdemir University Scientific Research Projects Coordination Unit and Advisor Prof. Dr. Yahya Erkan AKANSU for their supports.

\section{References}

[1] Bellman, M. Agarwal, R. Naber, J. and Chusak, L. (2010) Reducing energy consumption of ground vehicles by active flow control. In ASME 2010 4th International Conference on Energy Sustainability. pp 785-793. American Society of Mechanical Engineers.

[2] Moussa, A.A. Fischer, J. and Yadav, R. (2015). Aerodynamic Drag Reduction for a Generic Truck Using Geometrically Optimized Rear Cabin Bumps Journal of Engineering vol. (2015). pp:2-14.
[3] Jonathan, M. Erik, F. Gregory, R. Rajan, K. Kunihiko, T. Farrukh, A., Yoshihiro, Y. and Kei M. (2015). Drag reduction on a flat-back ground vehicle with active flow control. J. Wind Eng. Ind. Aerodyn. 145, 292-303.

[4] Shim, H.S. Lee, Y.N. Kim, K.Y. (2017). Optimization of bobsleigh bumper shape to reduce aerodynamic drag" Journal of Wind Engineering \& Industrial Aerodynamics $164,108-118$.

[5] Cui, W. Zhu, H. Xia, C. Yanga, Z. (2015). Comparison of steady blowing and synthetic jets for aerodynamic drag reduction of a simplified vehicle. Procedia Engineering $126,388-392$.

[6] Gurlek, C. Sahin, B. Ozkan, G.M. (2012). PIV studies around a bus model", Experimental Thermal and Fluid Science 38, 115-126.

[7] Lin, M. Dajun, Z. Wanshui H. Jun, W. and Jianxin, L. (2016). Transient aerodynamic forces of a vehicle passing through a bridge tower's wake region in crosswind environment. Wind and Structures, 22-2, 211-234.

[8] Ji-qiang, N. Dan, Z. Xi-feng, L.(2017). Experimental research on the aerodynamic characteristics of a highspeed train under different turbulence conditions. Experimental Thermal and Fluid Science 80,117-125.

[9] Chilbule, C. Upadhyay, A. Mukkamala, Y. (2014). Profile modification of truck-trailer to prune the aerodynamic drag and its repercussion on fuel consumption. Procedia Engineering 97, 1208 - 1219.

[10] Patil, C.N. Shashishekar, K.S. Balasubramanian, A.K. Subbaramaiah, S.V. (2012). Aerodynamic Study and drag coefficient optimization of passenger vehicle, International Journal of Engineering Research \& Technology (IJERT), 1-7, 1-8.

[11] Bayindirli, C. and Çelik, M. (2018). The Experimentally and Numerically Determination Of The Drag Coefficient Of A Bus Model International Journal of Automotive Engineering and Technologies, 7 (3) 117123.

[12] Çengel, Y.A., and Cimbala, J.M. (2008). Akışkanlar Mekaniği Temelleri ve Uygulamaları. Güven Bilimsel Yayınları, 562-599.

[13] Ince, İ.T.(2010). Aerodynamic Analysis of GTD Model Administrative Service Vehicle. PhD Thesis, Gazi Universty Institute of Science, Ankara, 30-66.

[14] Akansu, Y. E., Bayındırlı, C., Seyhan M. (2016). The improvement of drag force on a truc trailer vehicle by passive flow control methods, J. of Thermal Science and Technology, 36, 1, 133-141. 